\title{
Analysis of root-zone soil moisture control on evapotranspiration in two agriculture fields in Australia
}

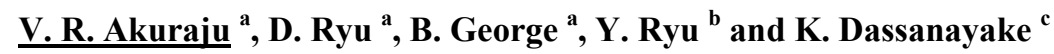 \\ ${ }^{a}$ Department of Infrastructure Engineering, The University of Melbourne, Parkville, Victoria,3010. \\ ${ }^{b}$ Department of Landscape Architecture and Rural Systems Engineering, Seoul National University, Seoul, \\ Republic of Korea \\ ${ }^{c}$ Melbourne School of Land and Environment, The University of Melbourne, Parkville, Victoria,3010. \\ Email: avenkataradha@gmail.com
}

\begin{abstract}
Soil moisture content in the root-zone is an important variable in modeling hydrological and biophysical processes and agricultural applications. For example, partitioning of surface energy exchange into the latent and the sensible heat fluxes is affected much by soil water content. Typically surface moisture content has been mapped using the microwave remote sensing techniques at large scales. In addition to the microwave remote sensing, there is a growing interest in mapping high-resolution soil moisture content using remotely sensed thermal signals or evapotranspiration (ET). This new technique is based on the assumption that the evaporative fraction (EF) or the ratio of actual ET to potential ET (AET: PET) is controlled by soil water content available for bare soil evaporation or vegetation transpiration. However, there are a number of environmental and biological factors contributing to EF and AET: PET such as the net radiation, vapor pressure deficit, vegetation biomass and growth stage, etc. This work investigates effectiveness of the EF and AET: PET based root-zone soil moisture estimation in the agricultural landscapes. In order to analyze the sensitivity of EF and AET/PET to soil moisture, meteorological and biophysical variables, we use continuous observations of surface reflectance, eddy-covariance ET, profile soil moisture and other meteorological variables collected by tower-based Spectro-Eddy-Covariance (SEC) systems installed in experimental farm sites in Victoria, Australia. Two SEC systems are installed in two rain-fed agricultural fields; wheat, pasture covered with lucerne. Statistical analyses were conducted to identify key contributors to EF and AET: PET, which can be ultimately used to constrain ET-based soil moisture estimation scheme.
\end{abstract}

The correlation between EF and AET/PET was good throughout the vegetation period with $R^{2}$ value 0.83 . Therefore, we showed that EF or AET: PET exhibits consistent correlations with soil water available for vegetation in both study sites. The exponential model appears to provide reasonable estimates of EF using soil moisture with $R^{2}$ value of 0.78 . The model performance was further decreased yielding an $R^{2}$ value of 0.52 with inclusion of bare soil conditions. EF vs. soil moisture at surface and root-zone is sensitive to vegetation biomass. For soil moisture $0-8 \mathrm{~cm}$, correlation is higher during bare soil condition while for $0-30$ $\mathrm{cm}$, correlation is significantly higher when there is enough biomass. The relation between the EF and soil moisture is strong when ET is water limited and correlation become weak when ET is energy limited. Implications are that, when estimating root-zone soil moisture using EF, we have to consider net radiation and NDVI greater at critical threshold levels and soil depth should be specified properly. Analysis indicates that the net radiation and NDVI are the most important factors, other than soil moisture, that influences the ET versus soil moisture relationship, and the influence varies with season.

Keywords: $\quad$ Evapotranspiration, Root-zone soil moisture, Thermal infrared remote sensing 
Akuraju et al., Analysis of root-zone soil moisture control on evapotranspiration in two agriculture fields in Australia

\section{INTRODUCTION}

Soil moisture is one of the important state variables in hydrological modelling, agricultural applications and biological processes. The exchange of energy and water between the land and atmosphere rely much on water content of the soil. For example, soil water content controls the evaporation and transpiration fluxes from bare soil and vegetated surfaces (Entekhabi et al., 1994). Soil moisture changes with time and significantly with depth and space. Different methods have been proposed for measuring soil moisture at different spatial scales from point to global scales. Conventional ground-based soil moisture instruments can provide precise soil moisture estimates at field scale; however it is difficult to extend them to larger spatial extents. Satellite remote sensing is a promising option for mapping surface soil moisture at regional to global scales. Passive microwave sensors can obtain the surface soil moisture information even under cloud cover, but their retrievals are available only at low resolutions and prone to large errors over densely vegetated regions (Wang et al. 1980). Also shallow soil moisture information from the microwave retrievals may not be useful when root-zone soil moisture is required such as in agricultural applications.

One possible avenue for filling this gap is to estimate the root-zone soil moisture information using thermal infrared (TIR) temperature or evapotranspiration from vegetated lands. Vegetation canopy temperature and evaporative fraction (EF) are sensitive to the vegetation water stress and consequently root-zone soil moisture (Schmugge 1988). EF is the ratio of latent heat flux to the sum of latent and sensible heat fluxes at the land surface (Shuttleworth 1989). Typically, optical satellite can produce TIR temperature and EF estimates at higher resolutions than microwave instruments. Over the last two decades, various techniques have been tried to estimate root-zone soil moisture by utilizing remotely sensed evapotranspiration or TIR temperature (e.g., Scott et al., 2003; Anderson et al., 2007; Crow et al., 2006; Li et al., 2010). For example, Scott et al. (2003) converted evapotranspiration estimated from the Surface Energy Balance Algorithm for Land (SEBAL) to root-zone soil water content based on statistical relationship between them. For most of these approaches, a soil moisture stress function, which relates available water fraction to EF, was used to convert ET to soil moisture. Although these approaches provide soil moisture information at high resolution, depth of retrieved soil moisture information and its relationship with rooting depth at various phenological stages have not been analyzed.

In addition to the direct conversion of EF to soil moisture, the surface TIR data or EF can be assimilated into energy and water balance models (e.g., Crow et al., 2006; Li et al., 2010; Hain et al.,2011). In these methods, TIR data or surface soil moisture information derived from soil latent heat flux was assimilated to updated model-predicted profile soil moisture contents.

One of the main limitations of these approaches is that dynamic interaction between soil moisture and evapotranspiration is not captured with enough frequency due to the lack of continuous optical measurements from satellites. Also, there are some important factors, such as net radiation and biomass (represented by the Normalized Difference Vegetation Index (NDVI)), that influence coupling between ET and soil moisture. In fact, detailed impact of environmental and biological factors on this relationship has not been well examined yet.

In this research, we explore the impacts of meteorological and vegetation biophysical conditions on EF versus multiple-depth soil moisture in the agricultural land scapes. It is hypothesized that correlation between EF and surface or root-zone soil moisture changes with soil wetness, net radiation, vegetation growth stage and biomass. Continuous measurements of hydro meteorological variables such as evapotranspiration, solar radiation, NDVI, profile soil moisture content, etc, collected at two study sites (wheat and lucerne fields) are used to examine EF vs. soil moisture under various

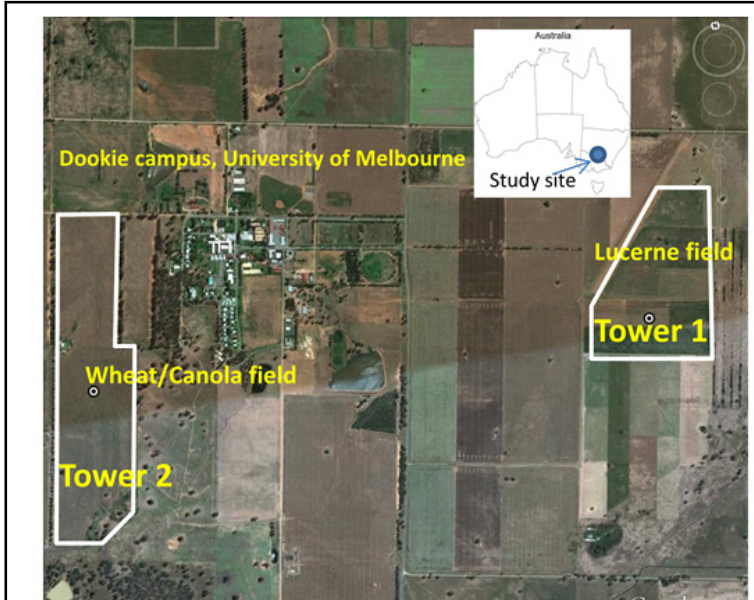

Figure 1. Location of the study sites at Dookie, Victoria, Australia. meteorological and biophysical conditions.

\section{STUDY SITE}

The study was conducted in two rain-fed agriculture fields at the Dookie campus, University of Melbourne. The study sites are located $220 \mathrm{~km}$ north-east of Melbourne, Victoria, Australia (Figure 1). The climate is distinctively semi-arid with hot/dry summer and cold/wet winter. Mean monthly temperatures ranges from $3^{\circ} \mathrm{C}$ 
Akuraju et al., Analysis of root-zone soil moisture control on evapotranspiration in two agriculture fields in Australia

in July-August to $32^{\circ} \mathrm{C}$ in January-February. The annual rainfall of the study area varies from $370 \mathrm{~mm}$ to 770 $\mathrm{mm}$. Two meteorological towers were installed in two different agriculture fields. Study site 1 is a pastureland covered with lucerne which is used for sheep grazing. Wheat and Canola are grown as rotational crops in study site 2 .

\section{DATASETS AND METHODS}

Turbulent fluxes, surface reflectance and soil moisture measurements were measured using tower based observations. Eddy covariance system was composed of a sonic anemometer (CSAT3, Campbell Scientific, Inc.), with water vapour and $\mathrm{CO}_{2}$ density open path IRGA gas analyser (LI7500, LI-COR Inc.) placed $2.6 \mathrm{~m}$ above ground level. The CNR1 net radiometer by Kipp \& Zonen was installed at $5.7 \mathrm{~m}$ height to measure net radiation. Ground-based surface reflectance measurements were carried out with SKR-1850 and SKR$1870 \mathrm{~A}$ radiometers (Skye instruments). The radiometers were installed at $5.7 \mathrm{~m}$ height to measure surface reflectance at six channels with wavelengths 527-537, 565-575, 620-670, 837-877, 1228-1248, 2110-2148 nm. Soil moisture probes (CS616) were installed vertically to measure the soil moisture at average depths of $0-8 \mathrm{~cm}, 0$ $30 \mathrm{~cm}, 30-60 \mathrm{~cm}, 60-90 \mathrm{~cm}$, and $90-120 \mathrm{~cm}$. The meteorological parameters such as air temperature, relative humidity, barometric pressure wind speed, wind direction, soil temperature and soil heat fluxes were measured in the study sites. Figure 2 shows the schematic diagram of the tower-based sensors installed in the study sites.

The sampling frequency of the eddy covariance measurements was $20 \mathrm{~Hz}$, which has been converted to 30-minute time steps for analysis. All the meteorological and ground measurements were recorded at 30-minute time intervals while surface reflectance measurements were recorded at 5-minute intervals. The surface reflectance dataset was aggregated to 30-minute average to match the observation time scale of other measurements.

This study uses the data acquired from 15 August to 31 December 2012 (data collection started 90 days after

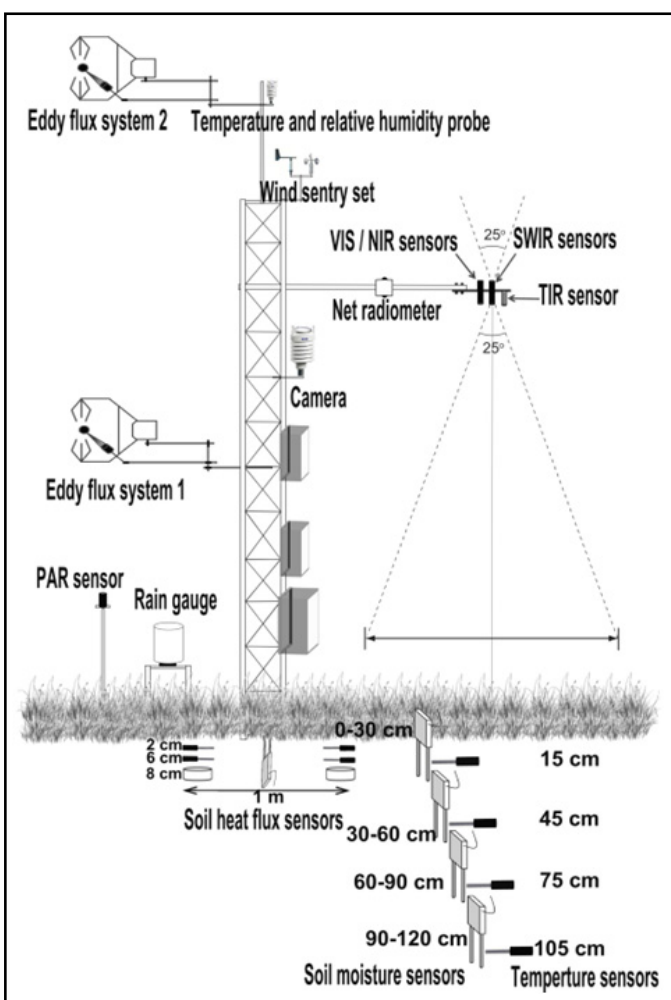

Figure 2. The diagram of eddy-covariance, spectral and soil moisture sensors installed in the study sites.

wheat was sown) at the wheat site and 1 March to 31 December 2012 at the lucerne site. Data gaps were filled in with linear interpolation method. For example, EC data was missed due to limited memory in data loggers and the gaps were filled using linear interpolation.

Potential (or 'reference') evapotranspiration was calculated using FAO Penman-Monteith equation (Allen 1998), which is based on the Penman-Monteith combination equation (Monteith, 1965). This method has been considered as a universal method to estimate potential/ reference evapotranspiration. Food and Agriculture Organization (FAO) committee defined the reference surface as "a hypothetical reference crop with an assumed height of $0.12 \mathrm{~m}$, surface resistance of $70 \mathrm{sm}^{-1}$ and an Albedo of 0.23" (Allen 1998). The FAO PenmanMonteith equation can be denoted as:

$$
E T_{0}=\frac{0.408 \Delta\left(R_{n}-G\right)+\gamma \frac{900}{T+273} U 2\left(e_{s}-e_{a}\right)}{\Delta+\gamma\left(1+0.34 U_{2}\right)}
$$

where $E T_{o}$ is potential/reference evapotranspiration in $m m d a y^{-1}, R_{n}$ is net radiation in $M J m^{-2} d a y^{-1}, G$ is the soil heat flux in $\mathrm{MJm}^{-2} \mathrm{day}^{-1}, \mathrm{~T}$ is air temperature in ${ }^{\circ} \mathrm{C}$ at $2 \mathrm{~m}$ height, $U_{2}$ is wind speed measured at $2 \mathrm{~m}$ height in $\mathrm{ms}^{-}$ ${ }^{l}, \Delta$ is the slope of the saturated vapour pressure curve and $\gamma$ is the psychrometric constant.

The meteorological data used for the potential evapotranspiration calculations were half-hourly averages of net radiation, soil heat flux, temperature, relative humidity, barometric pressure and wind speed, which were measured on the tower. Actual evapotranspiration (AET) has been obtained using latent heat flux 
Akuraju et al., Analysis of root-zone soil moisture control on evapotranspiration in two agriculture fields in Australia

measurements. Evaporative fraction (EF) has been obtained by averaging EFs for each latent heat and sensible heat flux measurements.

The correlation between EF and AET/PET was good throughout the vegetation period with $R^{2}$ value 0.83 . Most of the data points either fitted or were closely distributed around the 1:1 line. Figure 3(a) shows the correlation between EF and AET/PET in wheat vegetation conditions. AET/PET and EF values obtained from lucerne site dataset shows similar trend in vegetation periods with $R^{2}$ value 0.59 . Therefore, it is concluded that both EF and AET/PET can be used to estimate the root-zone soil water content, the use of EF seems to be more suitable where it can be derived in higher resolutions using TIR data.

To better understand the temporal changes of phenological stages, NDVI values were calculated by averaging the mid day values from $12 \mathrm{pm}$ to $2 \mathrm{pm}$. Due to atmospheric conditions such as cloud cover, time series of NDVI has erroneous results. A time series noise free NDVI has been produced by smooth out the noise using Savitzky-Golay filter.

Step wise multiple linear regression analysis has been carried out to identify factors that are significantly related to evapotranspiration and soil moisture using a set of independent variables collected from study sites. The results showed that there exists multi-co linearity between net radiation, NDVI, wind speed, air temperature, soil moisture and latent heat fluxes.

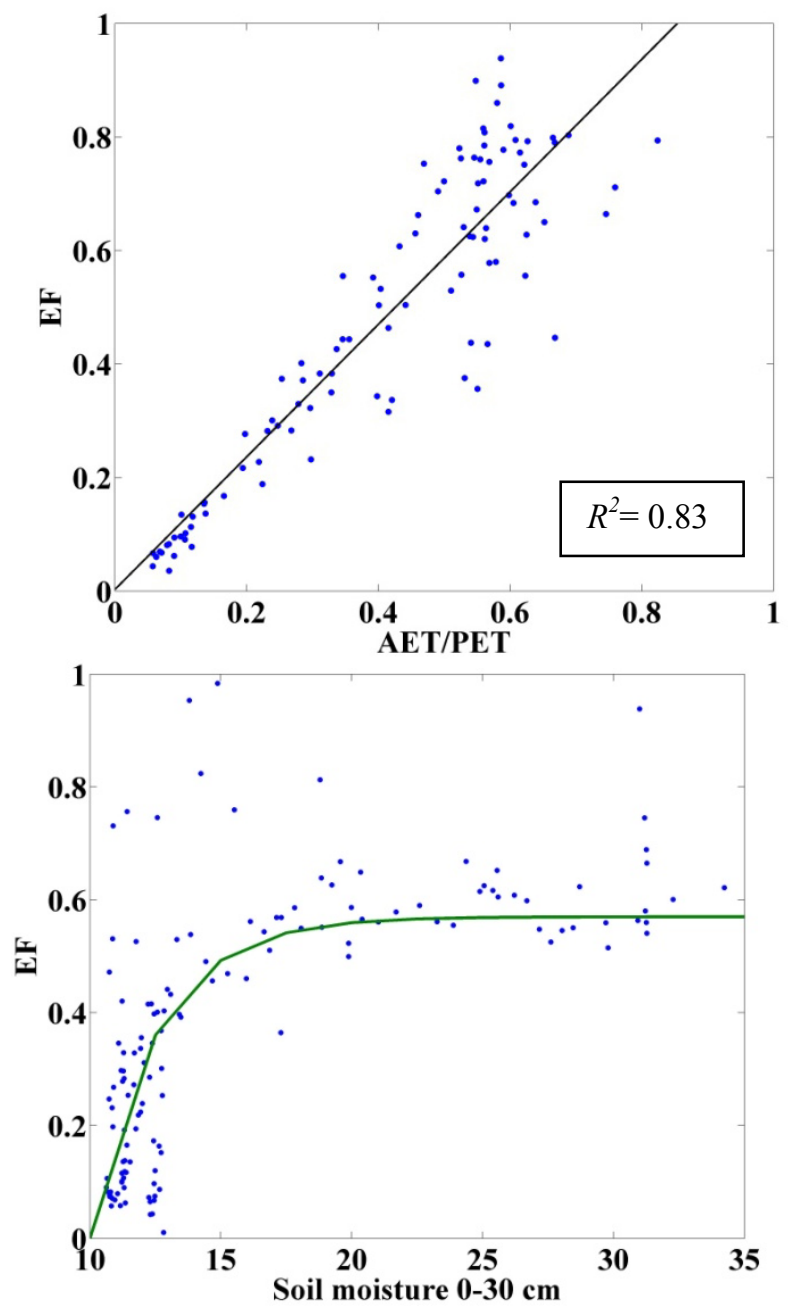

Figure 3. (a) Comparison of AET/PET and EF. (b) Exponential relationship between soil moisture 0-30 cm and evaporative fraction obtained from data collected in wheat site.

In order to find the relation between EF and soil moisture content, the data obtained from wheat site was used to fit a non-linear model. The exponential model appears to provide reasonable estimates of EF using soil moisture with $R^{2}$ value of 0.78 (see figure $3(\mathrm{~b})$ ). The root mean square difference of observed and modelled EF values is 0.09 . This can be compared to the errors associated with bare soil conditions. By adding the bare soil conditions, the model performance was further decreased yielding an $R^{2}$ value of 0.52 . In this case RMSD of observed and 
Akuraju et al., Analysis of root-zone soil moisture control on evapotranspiration in two agriculture fields in Australia

modelled EF values is 0.16 which demonstrates that the model performs well in vegetation conditions in compared to bare soil conditions.

\section{RESULTS AND DISCUSSION}

Analysis of this work mainly focuses on EF versus surface and root-zone soil moisture contents and environmental and biophysical factors influencing this relationship. Figure 4 shows the time series of the day time EF and NDVI at both sites. Figure 4 contains daily time series of EF and NDVI which was plotted against day of the year. In wheat site, vegetation cover increases rapidly in the beginning (started after 90 days of wheat sown) and reaches to its maximum after 40 days. NDVI values decrease monotonically, reflecting the likely influence of bare soil/harvested condition of wheat. In contrast to the wheat site, vegetation conditions changes suddenly in lucerne site due to sheep grazing activities. In lucerne site, the vegetation cover reaches its peak in the beginning and then declines with grazing activities (DOY 110, DOY 260 and DOY 300). EF values at the both sites increases with vegetation cover and reflecting the bare soil evaporation at end of the year. The seasonal pattern of NDVI and evaporative fraction were similar and relationship between NDVI and EF is more scattered when NDVI values are low. This means that influence of bare soil evaporation on EF is dominant during this period.
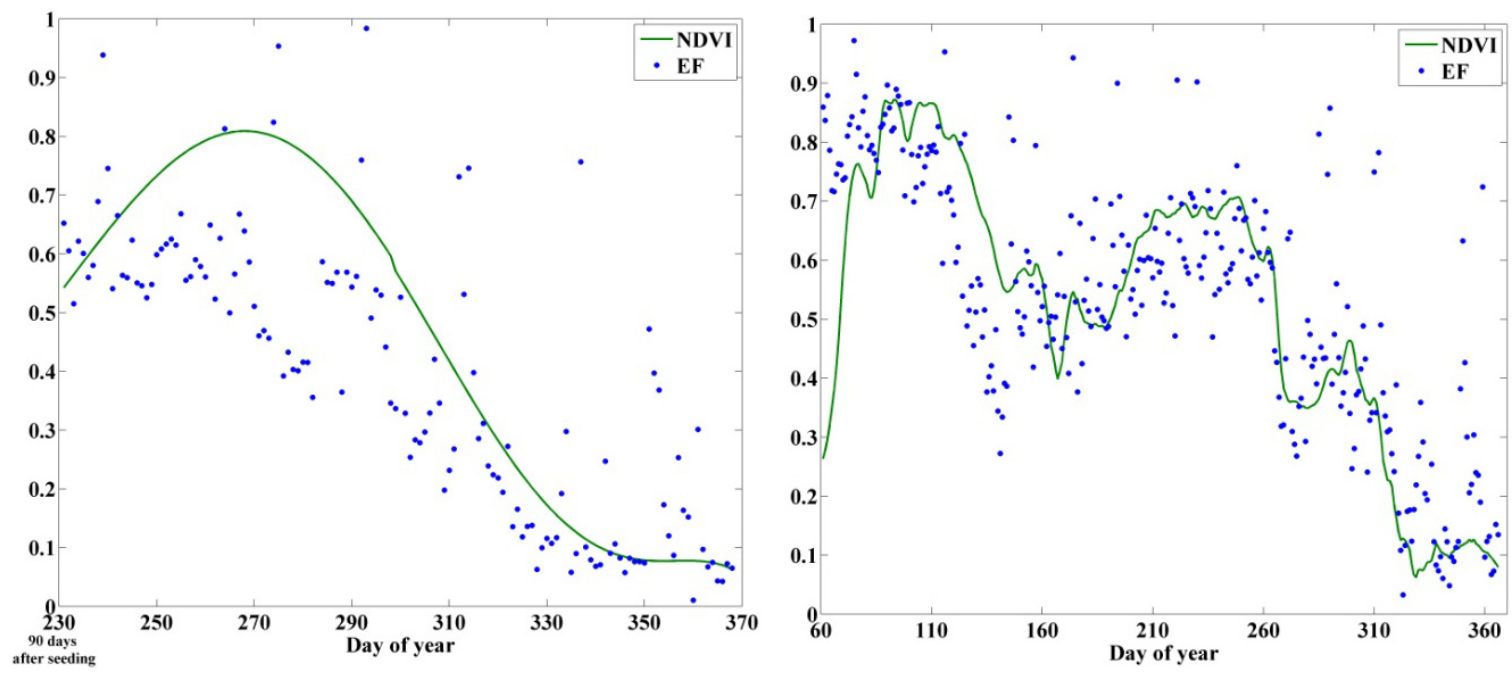

Figure 4. (a) Daily time series of EF and NDVI in wheat site. (b) Daily time series of EF and NDVI in lucerne site.

In this work, soil moisture at $0-8 \mathrm{~cm}$ was considered as surface soil moisture and soil moisture from $0-30 \mathrm{~cm}$ as root-zone soil moisture. Figure 5 shows the correlation between EF and soil moisture from 0-30 cm with respect to net radiation. The correlation is strong when ET is water limited and the relationship is weak when ET is energy limited. This can be compared to the errors associated with the subset of energy limited conditions. An important hypothesis here is that, beyond a certain threshold net radiation, there exists a strong relation between EF and soil water content. Net radiation values were calculated by averaging the mid day values from $12 \mathrm{pm}$ to $2 \mathrm{pm}$. This potential is examined in Table 1 which replicates figure 5 for the case of daily total EF. Root mean square error is 0.149 when $R_{n}$ is greater than $100 \mathrm{Wm}^{-2} . \mathrm{R}_{\mathrm{n}}$ leads to a further reduction in RMSD for different threshold levels. However, the magnitude of this reduction is sharply reducing number of samples. For instance, the EF retrievals with an (root-mean-square) error of 0.118 still leads to a substantial reduction in estimations, but has only a minor positive impact on EF. Based on different threshold values used in each round, it was noted that that the net radiation less than $250 \mathrm{Wm}^{-2}$ is influencing the ET and soil moisture relation (see Table 1). Other than net radiation, precipitation events may also influence the ET and soil moisture relations. Since EF was obtained from eddy covariance measurements which causes errors due to rainfall events. 
Akuraju et al., Analysis of root-zone soil moisture control on evapotranspiration in two agriculture fields in Australia

Table 1. Summary of different threshold levels of net radiation and error statistics of the exponential model.

\begin{tabular}{|c|c|c|c|c|c|c|}
\hline $\begin{array}{c}\text { Net radiation } \\
\text { threshold }\end{array}$ & $\begin{array}{c}\mathbf{> 1 0 0} \\
W m^{-2}\end{array}$ & $\begin{array}{c}\mathbf{> 1 5 0} \\
W m^{-2}\end{array}$ & $\begin{array}{c}\mathbf{2 0 0} \\
W m^{-2}\end{array}$ & $\begin{array}{c}\mathbf{> 2 5 0} \\
W m^{-2}\end{array}$ & $\begin{array}{c}\mathbf{3 0 0} \\
W m^{-2}\end{array}$ & $\begin{array}{c}>\mathbf{3 5 0} \\
W^{-2}\end{array}$ \\
\hline Sample size & 132 & 126 & 126 & 122 & 112 & 106 \\
\hline RMSE & 0.149 & 0.126 & 0.126 & 0.124 & 0.118 & 0.120 \\
\hline
\end{tabular}

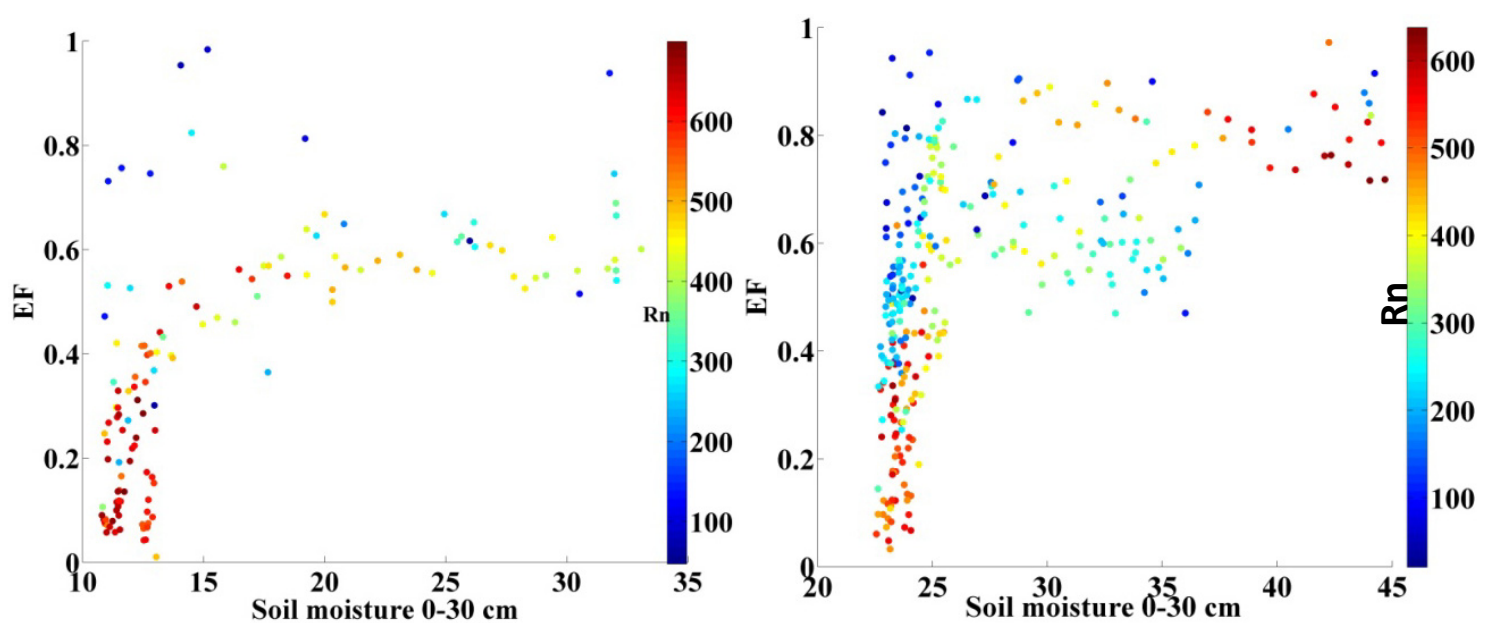

Figure 5. Scatter plot of EF vs. soil moisture from 0-30 cm with respect to net radiation in both study sites.

Analysis of the results from figures 4 and 5 shows that EF vs. surface soil moisture and root-zone soil moisture is sensitive to vegetation biomass which is quantified by NDVI. Soil moisture from $0-8 \mathrm{~cm}$ shows higher correlation during bare soil condition while soil moisture from $0-30 \mathrm{~cm}$ shows significantly higher correlation with ET when there is enough vegetation biomass. It was also found that the correlation between EF and soil moisture increases with depth of soil moisture with increasing trend of vegetation biomass.

To analyse the effectiveness of ET and soil moisture relations, the observations from lucerne site was plotted in figure 6 where external environmental factors (sheep grazing) influences the vegetation biomass conditions. From scatter plot of EF vs. soil moisture from $0-30 \mathrm{~cm}$ with respect to vegetation biomass, it can be observed that EF shows different levels in the scatter plot (Figure 6(b)). Most of the points in zone 1 indicate that ET is not vegetation biomass limited, but ET is water limited. Most of the points in zone 2 indicate that ET is not water limited, but ET is vegetation biomass limited.This means that relation of EF and soil moisture is greatly depends on vegetation biomass.
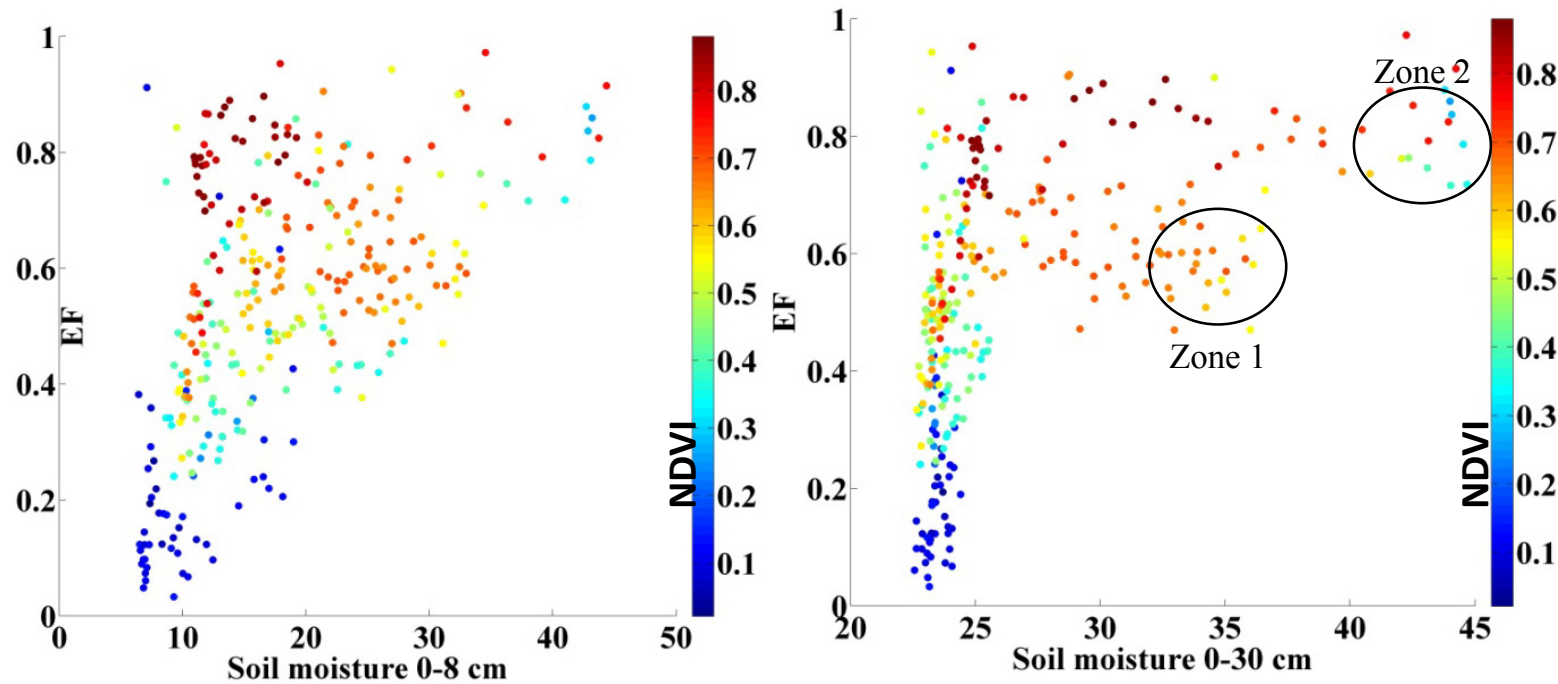

Figure 6. Scatter plot of EF and SM 0-30 cm in different vegetation biomass conditions at lucerne site 
Akuraju et al., Analysis of root-zone soil moisture control on evapotranspiration in two agriculture fields in Australia

The above results showed that there exists an exponential relationship between soil water content and evaporative fraction in both sites. Root-zone soil moisture can be obtained accurately when accurate ET is supplied at critical threshold levels of net radiation and vegetation biomass. Based on the method presented here, ET obtained from high resolution thermal data such as Landsat TM and MODIS can be used to produce spatial and temporal resolution of root-zone soil moisture.

\section{CONCLUSIONS}

This work investigated the EF or AET/PET based root-zone soil moisture estimations. It is hypothesized that EF exhibits consistent correlations with soil water available for vegetation. Environmental factors influencing on this relationship have not been examined yet. We show that the correlation between EF and soil moisture content is highly conditional on the vegetation biomass, net radiation, and the depth of soil. Based on the correlation between EF and SM at different levels, the following conclusions are derived: i) The correlation between the ET and SM is strong when ET is water limited and correlation become weak when ET is energy limited; ii) EF vs. soil moisture at surface and root-zone of soil is sensitive to vegetation biomass : for $0-8 \mathrm{~cm}$, correlation is higher during bare soil condition while for $0-30 \mathrm{~cm}$, correlation is significantly higher when there is enough biomass; iii) EF shows different levels, that is, ET is limited by vegetation biomass and ET is limited by energy limited conditions. Implications are that, when estimating root-zone soil moisture using EF, we have to use data for net radiation and NDVI greater at critical threshold levels and soil depth should be specified properly.

\section{ACKNOWLEDGEMENT}

The authors would like to thank Australian Centre for International Agriculture Research (ACIAR) for sponsoring the research under the John Allwright Fellowship. The authors would like to thank Rodger Ian Young and Robert Pipunic for their valuable support in data collection.

\section{REFERENCES}

Allen, R. G. (1998). Crop evapotranspiration : Guidelines for computing crop water requirements / by Richard G. Allen ... [et al.], Rome : FAO.

Anderson, M.C., J.M. Norman, J.R. Mecikalski, J.A. Otkin, and W.P. Kustas (2007). A climatological study of evapotranspiration and moisture stress across the continental United States based on thermal remote sensing: 1. Model formulation. Journal of Geophysical Research-Atmospheres, 112(D10).

Crow, W.T., W.P.Kustas, and J.H.Prueger (2006). Monitoring root-zone soil moisture through the assimilation of a thermal remote sensing-based soil moisture proxy into a water balance model. Remote Sensing of Environment ,112: 1268-1281.

Engman and C. Narinder (1995). Status of microwave soil moisture measurements with remote sensing. Remote Sensing of Environment, 51: 189-198.

Entekhabi, D., H. Nakamura, and E.G. Njoku (1994). Solving the inverse problems for soil-moisture and temperature profiles by sequential assimilation of multifrequency remotely-sensed observations. Ieee Transactions on Geoscience and Remote Sensing, 32(2).

Hain, C. R., W.T. Crow, J.R. Mecikalski, M.C. Anderson, and T.Holmes (2011). An intercomparison of available soil moisture estimates from thermal infrared and passive microwave remote sensing and land surface modeling. Journal of Geophysical Research-Atmospheres, 116.

Li, F., W.T.Crow and W.P.Kustas (2010). Towards the estimation root-zone soil moisture via the simultaneous assimilation of thermal and microwave soil moisture retrievals. Advances in Water Resources, 33: 201-214.

Monteith (1965). The state and movement of water in living organisms, New York, Published for the Company of Biologists on behalf of the Society for Experimental Biology [by] Academic Press.

Norman, J.M., W.P. Kustas, and K.S. Humes (1995). Source approach for estimating soil and vegetation energy fluxes in observations of directional radiometric surface-temperature. Agricultural and Forest Meteorology, 77,3-4.

Schmugge, T. (1998). Applications of passive microwave observations of surface soil moisture. Journal of Hydrology, 212,1-4.

Scott, C.A., W.G.M. Bastiaanssen, M.U.D. Ahmad (2003). Mapping root zone soil moisture using remotely sensed optical imagery. Journal of Irrigation and Drainage Engineering-ASCE 129(5), 326-335.

Shuttleworth, J. W., and R.J. Gurney (1989). FIFE:Thevariation in energy partition at surface flux site, IAHS, 186.

Wang, J.R., J.C. Shiue, J.E.McMurtrey (1980). Microwave remote sensing of soil moisture content over bare and vegetated fields. Geophysical Research Letters, 7,801-804. 